ARTICLE

https://doi.org/10.1038/s41467-019-12414-z

\title{
Carbon dioxide capture and efficient fixation in a dynamic porous coordination polymer
}

\author{
Pengyan Wu (1) ${ }^{1}$, Yang Li ${ }^{1}$, Jia-Jia Zheng ${ }^{2,3}$, Nobuhiko Hosono (i) ${ }^{2,4}$, Ken-ichi Otake ${ }^{2}$, Jian Wang (i) ${ }^{1 \star}$, \\ Yanhong Liu', Lingling Xia', Min Jiang ${ }^{1}$, Shigeyoshi Sakaki ${ }^{3} \&$ Susumu Kitagawa (1) ${ }^{2 \star}$
}

Direct structural information of confined $\mathrm{CO}_{2}$ in a micropore is important for elucidating its specific binding or activation mechanism. However, weak gas-binding ability and/or poor sample crystallinity after guest exchange hindered the development of efficient materials for $\mathrm{CO}_{2}$ incorporation, activation and conversion. Here, we present a dynamic porous coordination polymer (PCP) material with local flexibility, in which the propeller-like ligands rotate to permit $\mathrm{CO}_{2}$ trapping. This process can be characterized by $\mathrm{X}$-ray structural analysis. Owing to its high affinity towards $\mathrm{CO}_{2}$ and the confinement effect, the PCP exhibits high catalytic activity, rapid transformation dynamics, even high size selectivity to different substrates. Together with an excellent stability with turnover numbers (TON) of up to 39,000 per $\mathrm{Zn}_{1.5}$ cluster of catalyst after 10 cycles for $\mathrm{CO}_{2}$ cycloaddition to form value-added cyclic carbonates, these results demonstrate that such distinctive structure is responsible for visual $\mathrm{CO}_{2}$ capture and size-selective conversion.

\footnotetext{
${ }^{1}$ School of Chemistry and Materials Science, Jiangsu Key Laboratory of Green Synthetic Chemistry for Functional Materials, Jiangsu Normal University, 221116 Xuzhou, Jiangsu, China. ${ }^{2}$ Institute for Integrated Cell-Material Sciences, Kyoto University Institute for Advanced Study, Kyoto University, Yoshida Ushinomiya-cho, Sakyo-ku, Kyoto 606-8501, Japan. ${ }^{3}$ Fukui Institute for Fundamental Chemistry, Kyoto University, Nishi-hiraki cho, Takano, Sakyo-ku, Kyoto 606-8103, Japan. ${ }^{4}$ Present address: Department of Advanced Materials Science, Graduate School of Frontier Sciences, The University of Tokyo, 5-1-5 Kashiwanoha, Kashiwa, Chiba 277-8561, Japan. *email: wjian@jsnu.edu.cn; kitagawa@icems.kyoto-u.ac.jp
} 
T he huge consumption of fossil fuels has resulted in sharply rising levels of anthropogenic $\mathrm{CO}_{2}$ emission, leading to serious linkage problems associated with global warming and climate change $e^{1,2}$. Practical $\mathrm{CO}_{2}$ capture and sequestration (CCS) are currently usually limited to extensive energy input during desorption and compression processes ${ }^{3-5}$. Captured $\mathrm{CO}_{2}$ should ideally be synchronously converted into high-value chemicals, allowing the emitted $\mathrm{CO}_{2}$ to be reused in carbon cycling processes. One of the greenest approaches is cycloaddition of $\mathrm{CO}_{2}$ to epoxides, a $100 \%$ atom-economical reaction, to form cyclic carbonates, which have numerous applications in petrochemicals, fine chemicals, and pharmaceuticals ${ }^{6-9}$. The relatively low reactivity and kinetic inertness of $\mathrm{CO}_{2}$ make it essential to develop efficient catalytic systems for its incorporation, activation, and conversion. Furthermore, direct structural information of the molecular state of captured $\mathrm{CO}_{2}$ by X-ray diffraction (XRD) techniques is invaluable despite the practical difficulties associated with its gaseous nature because this not only enables a thorough understanding of the specific host-guest interaction or activation mechanism and processes, but also leads to the development of new and improved catalysts. A limited number of reports ${ }^{10-13}$ revealed that commensurate $\mathrm{CO}_{2}$-trapping crystal structures were produced when the host has sufficient flexibility to trap guest molecules, resulting in a high probability of developing gas-trapping structures.

Porous coordination polymers (PCPs) or metal-organic frameworks (MOFs) are emerging as a promising class of crystalline porous materials with wide applications, including gas adsorption and storage $\mathrm{e}^{14,15}$ and heterogeneous catalysis ${ }^{16-18}$. PCPs therefore have an advantage over other catalysts with respect to $\mathrm{CO}_{2}$ chemistry because of their integration of the inherent sorptive behavior with the uniform Lewis/Brønsted acidic or basic active sites endowed by their facile tunability and modular nature, as well as their ultra-high surface area and heterogeneous nature ${ }^{19-21}$. Furthermore, flexibility and softness in spatial and electronic structures can provide a dynamic space that transforms in response to guest trapping ${ }^{22-24}$. Flexible structures usually have lower thermal stability than rigid structures in a single network; however, this problem can be overcome by interpenetration ${ }^{25}$. Despite this, the location of $\mathrm{CO}_{2}$ molecules in an interpenetrated PCP crystal has not yet been reported. PCPs also impose size-slective and shape-selective restrictions through readily fine-tuned channels and pores, displaying a molecular sieving effect ${ }^{26,27}$. Thus our aim is to introduce local flexibility, so effectively that $\mathrm{CO}_{2}$ are captured by size and shape-induced fit, and also that all the reactants still possess degree of freedom for the coupling reaction.

Here, we report the successful design of a two-fold interpenetrated framework, Zn-DPA. $2 \mathrm{H}_{2} \mathrm{O} \quad\left(\mathbf{D P A}=4,4^{\prime}, 4^{\prime \prime}\right.$-tricarboxyltriphenylamine and (E)-1,2-di-(pyridin-4- yl)diazene). Their propeller-like ligands $4,4^{\prime}, 4^{\prime \prime}$ - tricarboxyltriphenylamine undergo rotational rearrangement in response to the release and capture of guest molecules, resulting in slight changes of their channels. The PCP shows a high affinity towards $\mathrm{CO}_{2}$ molecules, which is clearly verified by the single-crystal structure of the $\mathrm{CO}_{2}$-adsorbed phases and its high catalytic efficiency and size selectivity with respect to $\mathrm{CO}_{2}$ cycloaddition to epoxides.

\section{Results}

Synthesis and characterization of $\mathrm{Zn}-\mathrm{DPA} \cdot 2 \mathrm{H}_{2} \mathrm{O}$ and $\mathrm{Zn}$-DPA. The reaction of $\mathrm{Zn}\left(\mathrm{NO}_{3}\right)_{2} \cdot 6 \mathrm{H}_{2} \mathrm{O}, 4,4^{\prime}, 4^{\prime \prime}$-tricarboxyltriphenylamine $\left(\mathrm{H}_{3} \mathrm{tca}\right)$ and (E)-1,2-di(pyridin-4-yl)diazene (dpa) under solvothermal condition gave red crystals $\mathrm{Zn}-\mathrm{DPA} \cdot 2 \mathrm{H}_{2} \mathrm{O}\left\{\left[\mathrm{Zn}_{1.5}(\mathrm{tca})\right.\right.$ $\left.\left.(\mathrm{dpa})_{0.5}\right] \cdot 2 \mathrm{H}_{2} \mathrm{O}\right\}_{n}$ in high yield (82\%). A single-crystal XRD study revealed that $\mathrm{Zn}$-DPA $2 \mathrm{H}_{2} \mathrm{O}$ crystallizes in monoclinic space group
C2/c. The asymmetric unit of Zn-DPA- $2 \mathrm{H}_{2} \mathrm{O}$ contains one and a half $\mathrm{Zn}^{2+}$ ions, one deprotonated tca ${ }^{3-}$ anion, half of a dpa ligand and two lattice water molecules. The $\mathrm{Zn}(1)$ atom is hexacoordinated by six carboxylate oxygen atoms belonging to six different $\mathrm{tca}^{3-}$ ligands, forming an octahedral geometry. The $\mathrm{Zn}(2)$ atom is surrounded by four oxygen atoms from three $\mathrm{tca}^{3-}$ ligands and one nitrogen atom from one dpa ligand in a pseudo-tetragonal pyramid geometry (Supplementary Fig. 1). Adjacent Zn(II) centers are linked by carboxylate oxygen atoms of $\mathrm{tca}^{3-}$ ligands with a $\mathrm{Zn} 1 \cdots \mathrm{Zn} 2$ separation of 3.338(2) $\AA$, forming a trinuclear $\mathrm{Zn}_{3}\left(\mathrm{CO}_{2}\right)_{6}$ unit (Supplementary Fig. 2). It is noteworthy that two unsaturated zinc centers on both ends of a trinuclear unit are well-oriented toward the channels, facilitating their full accessibility for the substrates to their open sites of Lewis acidic centers (Supplementary Fig. 3).

The $\mathrm{tca}^{3-}$ ion resembles a propeller with the central nitrogen having $s p^{2}$ hybridization, since its phenyl rings are tilted relative to each other with dihedral angles of $78.2(6)^{\circ}, 80.6^{\circ}$, and $87.6(9)^{\circ}$ (Fig. 1a). The dihedral angle between the phenyl rings of two $\mathrm{tca}^{3-}$ ligands located at the trans position of the $\mathrm{Zn}_{3}\left(\mathrm{CO}_{2}\right)_{6}$ cluster is $0.0^{\circ}$, and the $\mathrm{N} \cdots \mathrm{N}$ distance between these ligands is 16.57 and 16.84(3) $\AA$ (Supplementary Fig. 5). Each tca ${ }^{3-}$ ligand-linked six $\mathrm{Zn}(\mathrm{II})$ centers in a $\mu_{6}-\eta^{1}: \eta^{1}: \eta^{1}: \eta^{1}: \eta^{1}: \eta^{2}$ manner to form an infinite two-dimensional (2D) sheet parallel to the $a b$ plane (Supplementary Fig. 4); these adjacent layers are further pillared in the third dimension by accessorial dpa ligands through their pyridine groups to afford an extended 3D coordination framework with one-dimensional rectangular channels of ca. $13.2 \times 9.7 \AA^{2}$ along the $b$-axis (Supplementary Fig. 6). This exhibits a two-nodal $(3,8)$ connected tfz-d topology with the $\left(4^{3}\right)_{2}\left(4^{6} \cdot 6^{18} \cdot 8^{4}\right)$ Schläfli symbol (Supplementary Fig. 7). Notably, the large channel allows the penetration of another identical net; thus, the entire structure of Zn-DPA $2 \mathrm{H}_{2} \mathrm{O}$ is a two-fold interpenetrated $3 \mathrm{D}$ net (Fig. 1b). The interpenetrated nets are connected through $\mathrm{C}-\mathrm{H} \cdots \pi$ interactions (spacing ca. $3.15 \AA$ ). Despite interpenetration, three-dimensionally running channels with cross-sections of $5.8 \times 11.5 \AA^{2}$ are still observed along the $b$-axis (Fig. 1c and Supplementary Fig. 3 ). The solvent-accessible volume calculated by the PLATON program is $1883.3 \AA^{3}$, which is $31.6 \%$ of the unit-cell volume.

The thermogravimetric analysis curve of Zn-DPA. $2 \mathrm{H}_{2} \mathrm{O}$ reveals that the lattice water molecules are removed by heating and that the coordination framework is thermally stable up to ca. $260^{\circ} \mathrm{C}$. Thus, desolvation was accomplished by heating assynthesized Zn-DPA $2 \mathrm{H}_{2} \mathrm{O}$ at $120^{\circ} \mathrm{C}$ under vacuum for $32 \mathrm{~h}$ to generate desolvated $\mathrm{Zn}-\mathrm{DPA}\left\{\left[\mathrm{Zn}_{1.5}(\mathrm{tca})(\mathrm{dpa})_{0.5}\right]\right\}_{n}$, and TGA (Supplementary Fig. 8) clearly indicated that the guest water molecules were completely excluded. Single-crystal XRD of desolvated Zn-DPA indicated that Zn-DPA has a similar unitcell volume with minor distortions $\left(\Delta \mathrm{V} / \mathrm{V}_{\mathrm{Zn}-\mathrm{DPA} \cdot 2 \mathrm{H} 2 \mathrm{O}}=0.45 \%\right.$, $\Delta \beta=+0.4^{\circ}$ ) compared to Zn-DPA $2 \mathrm{H}_{2} \mathrm{O}$ (Supplementary Table 1). Three phenyl rings of the tca ${ }^{3-}$ units undergo minor rotational rearrangements upon desolvation, resulting in dihedral angles relative to each other of $80.7(6)^{\circ}, 81.8(5)^{\circ}$, and $86.6(9)^{\circ}$ (Fig. 1d). Two phenyl rings of the $\mathrm{tca}^{3-}$ ligands located at the trans position around the $\mathrm{Zn}_{3}\left(\mathrm{CO}_{2}\right)_{6}$ cluster remain parallel to each other (dihedral angle, $0.0^{\circ}$ ); however, one of $\mathrm{N} \cdots \mathrm{N}$ distance between these two tca ${ }^{3-}$ ligands decreases to 16.56(5) $\AA$ (Supplementary Fig. 5). This also leads to corresponding small changes in many of the key dihedral angles and torsion angles, which are summarized in Supplementary Table 2. In particular, the torsion angle of $\mathrm{O}-\mathrm{Zn}-\mathrm{O}-\mathrm{C}$ changes from $-3.08^{\circ}$ and $-56.95^{\circ}$ to $1.30^{\circ}$ and $-58.64^{\circ}$. Detailed analysis revealed small but non-negligible framework deformations. There was a minimal variation in the interlayer distance between the $2 \mathrm{D}$ sheets and the angle between the sides of the $3 \mathrm{D}$ net, and the distance between the different interpenetrated nets increased 

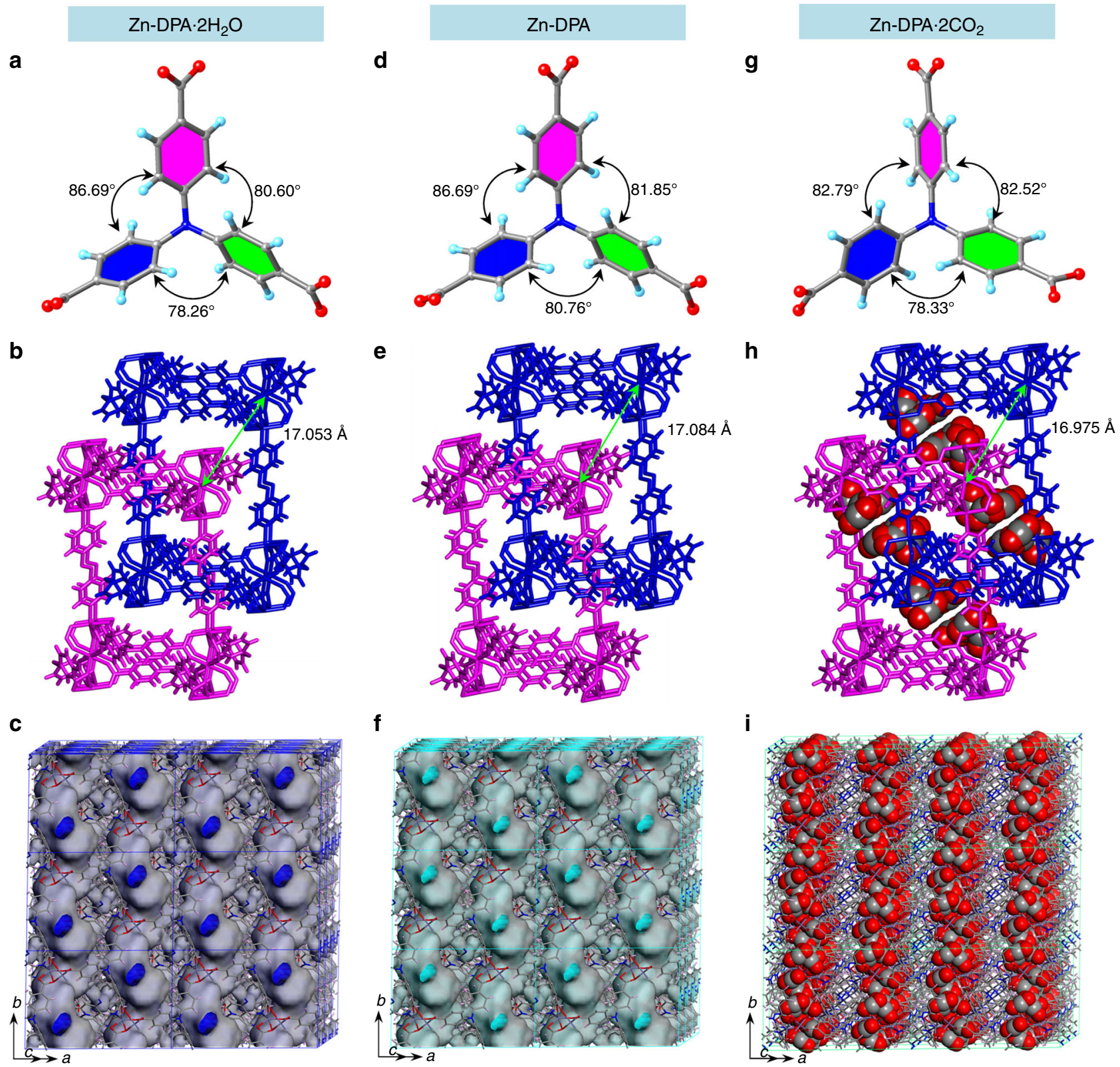

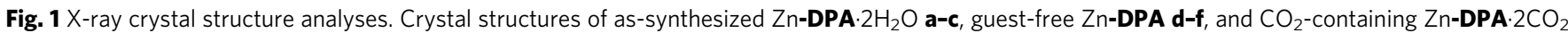
$\mathbf{g}-\mathbf{i}$. The dihedral angle between two phenyl rings relative to each other in tca ${ }^{3-}$ ligands found in PCPs a, $\mathbf{d}, \mathbf{g}$. The two-fold interpenetrated frameworks composed of a trinuclear $\mathrm{Zn}$ cluster, tca ${ }^{3-}$, and dpa ligands, showing the interlayer distance between the 2D sheets (measured between adjacent $\mathrm{Zn}$ cations from different sheets) $\mathbf{b}, \mathbf{e}, \mathbf{h}$. Three-dimensionally connected channels in PCPs with Connolly surfaces (Connolly radius: $1.6 \AA$ ). The inner surfaces of the channels are shown in blue for $\mathbf{c}$, cyan for $\mathbf{f}$, and green for $\mathbf{i}$, while the outer surfaces are represented in grey. Water molecules are omitted for clarity for $\mathrm{Zn}$-DPA- $2 \mathrm{H}_{2} \mathrm{O}$

slightly from $17.053 \AA$ in Zn-DPA. $2 \mathrm{H}_{2} \mathrm{O}$ to $17.084 \AA$ in Zn-DPA (Fig. 1e); thus, the main channels (void volume: $31.6 \%$ ) are still remained. A careful comparison of the two powder X-ray diffraction (PXRD) patterns of as-synthesized Zn-DPA- $2 \mathrm{H}_{2} \mathrm{O}$ and Zn-DPA also further confirmed that their frameworks remained almost unchanged (Supplementary Fig. 9).

Direct observation of $\mathrm{CO}_{2}$ molecules trapped in $\mathrm{Zn}$-DPA. Desolvated $\mathrm{Zn}$-DPA shows no obvious sorption of $\mathrm{N}_{2}$ at $77 \mathrm{~K}$ (Supplementary Fig. 10). At $195 \mathrm{~K}, \mathrm{CO}_{2}$ sorption by Zn-DPA gave a reversible Type-I isotherm without hysteresis (Fig. 2a), indicating that the effective micropore filling occurs for $\mathrm{CO}_{2}$. The saturated $\mathrm{CO}_{2}$ uptake was about $78.4 \mathrm{~cm}^{3} \mathrm{~g}^{-1}$, corresponding to $15.6 \mathrm{wt} \%$ or $2.0 \mathrm{CO}_{2}$ per formula unit. The
Brunauer-Emmett-Teller (BET) surface area of Zn-DPA was determined as $283 \mathrm{~m}^{2} \mathrm{~g}^{-1}$. At 273 and $293 \mathrm{~K}$, the adsorption isotherms of $\mathrm{CO}_{2}$ show a gradual increase and reach maximal amounts of $44.5 \mathrm{~cm}^{3} \mathrm{~g}^{-1}(8.7 \mathrm{wt} \%)$ and $34.8 \mathrm{~cm}^{3} \mathrm{~g}^{-1}$ (6.8 wt\%), respectively. The coverage-dependent $\mathrm{CO}_{2}$ adsorption enthalpy $\left(Q_{\text {st }}\right)$ of Zn-DPA was calculated using the Clausius-Clapeyron equation based on isotherms measured at 273 and $293 \mathrm{~K}$ (Fig. $2 \mathrm{~b}$ and Supplementary Fig. 11). The obtained $Q_{\text {st }}$ was found to be in the range $29.4-32.4 \mathrm{~kJ} \mathrm{~mol}^{-1}$ by fitting the data to the virial model ${ }^{28}$. The high $Q_{\text {st }}$ may indicate strong interactions between the $\mathrm{Zn}-\mathrm{DPA}$ coordination framework and $\mathrm{CO}_{2}$ guests.

To determine the interactions between the $\mathrm{CO}_{2}$ adsorbate and the constructed frameworks, a single crystal of evacuated 

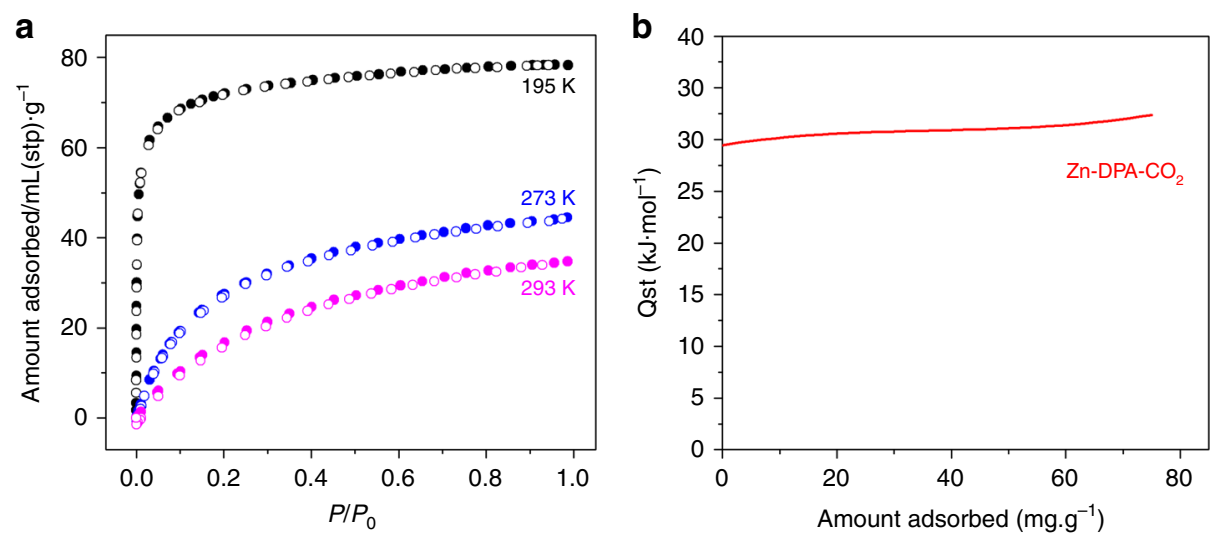

Fig. 2 Isotherms and isosteric heats of $\mathrm{CO}_{2}$ sorption. a $\mathrm{CO}_{2}$ adsorption isotherms for $\mathrm{Zn}-\mathbf{D P A}$ at $195 \mathrm{~K}$ (black), $273 \mathrm{~K}$ (blue), and $293 \mathrm{~K}$ (purple); stp is standard temperature and pressure. $\mathbf{b}$ Isosteric heats of $\mathrm{CO}_{2}$ adsorption for $\mathrm{Zn}$-DPA

Zn-DPA was fixed inside a glass capillary and sealed with backfilled $\mathrm{CO}_{2}(101 \mathrm{kPa}, 195 \mathrm{~K})$. The resulting $\mathrm{CO}_{2}$-loaded single crystal can be characterized with a conventional X-ray diffractometer at $183 \mathrm{~K}$, where $\mathrm{Zn}$-DPA could absorb two $\mathrm{CO}_{2}$ molecules per formula unit (Fig. 1h, i). Within each pore, three types of independent $\mathrm{CO}_{2}$-binding sites were located: $\mathrm{CO}_{2}-\mathrm{I}[\mathrm{O}(1 \mathrm{~A})-\mathrm{C}$ $(1 \mathrm{~A})-\mathrm{O}(2 \mathrm{~A})], \mathrm{CO}_{2}$-II with slight disorder $[\mathrm{O}(1 \mathrm{C})-\mathrm{C}(1 \mathrm{C})-\mathrm{O}(2 \mathrm{C})$, and $\mathrm{O}(1 \mathrm{CC})-\mathrm{C}(1 \mathrm{CC})-\mathrm{O}(2 \mathrm{CC})]$ and $\mathrm{CO}_{2}$-III $[\mathrm{O}(1 \mathrm{~B})-\mathrm{C}(1 \mathrm{~B})-\mathrm{O}$ (2B)]. Compared with the structure of the dried Zn-DPA, the unit cell of $\mathrm{Zn}-\mathrm{DPA} \cdot \mathrm{CO}_{2}$ displays a slight expansion and an obvious distortion $\left(\Delta V / V_{\mathrm{Zn}-\mathrm{DPA}}=0.34 \%, \Delta \beta=+0.2^{\circ}\right) \quad$ (Supplementary Table 1). The dihedral angles of the $\mathrm{tca}^{3-}$ ligands are $78.3(3)^{\circ}$, $82.5(2)^{\circ}$, and $82.7(9)^{\circ}$ (Fig. $1 \mathrm{~g}$ ). It was found that $\mathrm{CO}_{2}$-I was $77 \%$ occupancy, adjacent to the unsaturated zinc center, formed the electrostatic interaction in end-on fashion with a $\mathrm{Zn}-\mathrm{O}$ distance of 3.17(1) $\AA$, which was significantly shorter than the sum of van der Waals radii of zinc $(2.10 \AA)$ and oxygen $(1.52 \AA)$. The $\mathrm{C}(\delta+)$ atom of $\mathrm{CO}_{2}$-I also interacts with two carboxylate $\mathrm{O}$ atoms from $\mathrm{tca}^{3-}$ ligands $\left[\mathrm{C}(\delta+)\left(\mathrm{CO}_{2}\right) \cdots \mathrm{O}(\delta-)(\mathrm{tca})=3.13(2), \quad 3.22(9) \AA\right]$. Another $\mathrm{O}$ of $\mathrm{CO}_{2}$ interacts with the pyridyl $\mathrm{H}$ atom of dpa ligands and phenyl $\mathrm{H}$ atom of $\mathrm{tca}^{3-}$ ligands via $\mathrm{C}-\mathrm{H} \ldots \mathrm{O}$ hydrogen bonding with short $\mathrm{H}$... O distances of 2.64(7), 2.88 (2) $\AA$, respectively (Supplementary Fig. 12). $\mathrm{CO}_{2}$-II (64\% occupancy) and $\mathrm{CO}_{2}$-III (59\% occupancy) are located between $\mathrm{tca}^{3-}$ ligands via the host-guest $\mathrm{C}-\mathrm{H}$... O interactions (2.68(6) $\AA$

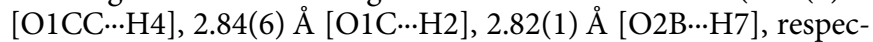
tively). In addition, $\mathrm{CO}_{2}$-I molecule interacts with neighbor $\mathrm{CO}_{2}$ II and $\mathrm{CO}_{2}$-III in T-shaped $[(\mathrm{C}(\delta+) \cdots \mathrm{O}(\delta-)=3.90(9) \AA$, $\mathrm{C} 1 \mathrm{~A} \cdots \mathrm{O} 2 \mathrm{CC}]$ and slipped parallel conformation $[\mathrm{C} \cdots \mathrm{C}=3.70$ (3) $\AA, \mathrm{C} 1 \mathrm{~A} \cdots \mathrm{C} 1 \mathrm{~B} ; 3.26(3) \AA$, C1A …C1C]. The distance between the different interpenetrated nets is $16.975 \AA$ and the void volume is $31.6 \%$ (when $\mathrm{CO}_{2}$ molecules are omitted) upon $\mathrm{CO}_{2}$ adsorption (Fig. 1h).

Furthermore, the canonical Monte Carlo (MC) simulations followed by geometry optimization using the PBE-D3 functional 29,30 indicate that $\mathrm{CO}_{2}$ molecules are found at three sites, which agree with the experimental result. The PBE-D3calculated binding energy (BE) for adsorption of one $\mathrm{CO}_{2}$ molecule in Zn-DPA decreases following the order site $\mathrm{I}>$ site $\mathrm{III} \approx$ site II, suggesting that the site $\mathrm{I}$ is the most favorable for $\mathrm{CO}_{2}$ adsorption at low loading (Supplementary Fig. 13). This result was analyzed by using the $E_{\mathrm{INT}}(\mathrm{H}-\mathrm{G})$ between $\mathrm{CO}_{2}$ and $\mathrm{Zn}-\mathrm{DPA}$ and $E_{\mathrm{DEF}}(\mathrm{H})$ of Zn-DPA. Because $E_{\mathrm{DEF}}(\mathrm{G})$ is negligibly small, it is not discussed herein. The $E_{\mathrm{DEF}}(\mathrm{H})$ is similar among the sites I, II, and III (Supplementary Table 3). However, the $E_{\mathrm{INT}}(\mathrm{H}-\mathrm{G})$ at the site $\mathrm{I}\left(-9.88 \mathrm{kcal} \mathrm{mol}^{-1}\right)$ is much larger (much more negative) than at the sites II and III. This $E_{\mathrm{INT}}(\mathrm{H}-\mathrm{G})$ at the site I mainly arises from the electrostatic interactions of $\mathrm{CO}_{2}$ molecule with $\mathrm{Zn}^{2+}$ and carboxylates because the negatively charged $\mathrm{O}$ atom approaches the positively charged $\mathrm{Zn}$ atom and the positively charged $\mathrm{C}$ atom approaches the negatively charged $\mathrm{O}$ atom of the carboxylates (Supplementary Fig. 14). Because the $\mathrm{Zn}^{2+}-\mathrm{CO}_{2}$ interaction is absent at the sites II and III, the $E_{\mathrm{INT}}(\mathrm{H}-\mathrm{G})$ is weaker at these sites than at the site I. This is the reason why the site $\mathrm{I}$ exhibits the largest (most negative) $\mathrm{CO}_{2}$ binding energy. These results indicate that $\mathrm{CO}_{2}$ adsorption into $\mathrm{Zn}$-DPA is likely to occur first at the site $\mathrm{I}$ and then $\mathrm{CO}_{2}$ adsorption starts to occur at the site II or III. The present calculations also showed the $B E$ value is similar between the sites II and III in the presence of $8 \mathrm{CO}_{2}$ molecules at the site I (Supplementary Table 4), exhibiting that $\mathrm{CO}_{2}$ adsorption similarly occurs at these sites II and III. These computational results are consistent with the experimental results by the singlecrystal XRD that $\mathrm{CO}_{2}$ molecules are found in similar occupancy at both of the sites II and III but the probability is lower than that at the site I. Thus, the combined experimental and computational results suggest that $\mathrm{Zn}$-DPA has a high $\mathrm{CO}_{2}$-binding affinity and could activate $\mathrm{CO}_{2}$.

Size-selective fixation of captured $\mathrm{CO}_{2}$ in $\mathrm{Zn}$-DPA. The ability of $\mathrm{CO}_{2}$ capture and the Lewis acid metal sites embedded in its framework suggest that Zn-DPA is a highly promising sizeselective heterogeneous catalyst for reactions of $\mathrm{CO}_{2}$ with substrate. Our catalytic experiments focused on the cycloaddition of carbon dioxide and epoxides. This reaction was performed with $\mathrm{Zn}-\mathrm{DPA}$ in an autoclave reactor at $1 \mathrm{MPa}$ and $373 \mathrm{~K}$. A small aliquot of the supernatant reaction mixture was analyzed by nuclear magnetic resonance spectroscopy $\left({ }^{1} \mathrm{H}\right.$ NMR) to calculate the reaction yield (Supplementary Fig. 15). As shown in Table 1, the transformation was initially examined by using 2-(phenoxymethyl)oxirane $(20 \mathrm{mmol})$ and $\mathrm{CO}_{2}$ as the coupling partners, along with $5 \mu \mathrm{mol}$ of $\mathrm{Zn}$-DPA (based on $\mathrm{Zn}_{1.5}$ cluster) and cocatalytic amounts $(0.3 \mathrm{mmol})$ of tetrabutylammonium bromide (TBABr). The results indicated that Zn-DPA can serve as an effective catalyst for the solvent-free synthesis of cyclic carbonates, affording an almost complete conversion within $2 \mathrm{~h}$. The turnover number (TON) was $\sim 4000$ per $\mathrm{Zn}_{1.5}$ cluster of $\mathrm{Zn-DPA}$, and the turnover frequency (TOF) was $\sim 2000$ per $\mathrm{Zn}_{1.5}$ cluster of Zn-DPA per hour. To the best of our knowledge, these values are higher than all of those previously reported for MOF-based catalysts in the cycloaddition of carbon dioxide to epoxides under similar conditions ${ }^{19,31}$. Several control experiments were conducted, e.g. the absence of any of the individual components, 


\section{Table $1 \mathrm{Zn}$-DPA-catalyzed coupling of epoxides with $\mathrm{CO}_{2}{ }^{\mathrm{a}}$}

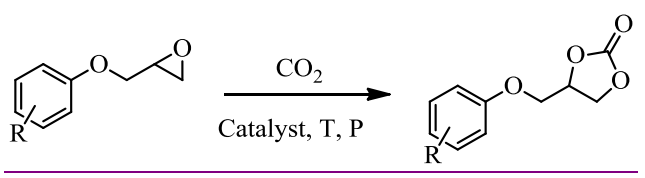

$\begin{array}{lll}\text { Entry } & \text { Epoxides } \\ 1 & \end{array}$

$\underline{3}$

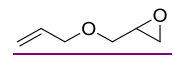

$\underline{4}$

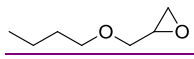

$\underline{5}$

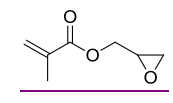

$\underline{6}$

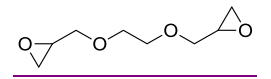

$\underline{7}$

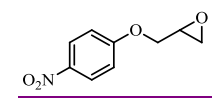

$\underline{8}$

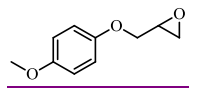

$\underline{9}$

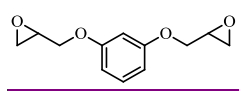

$\underline{10}$
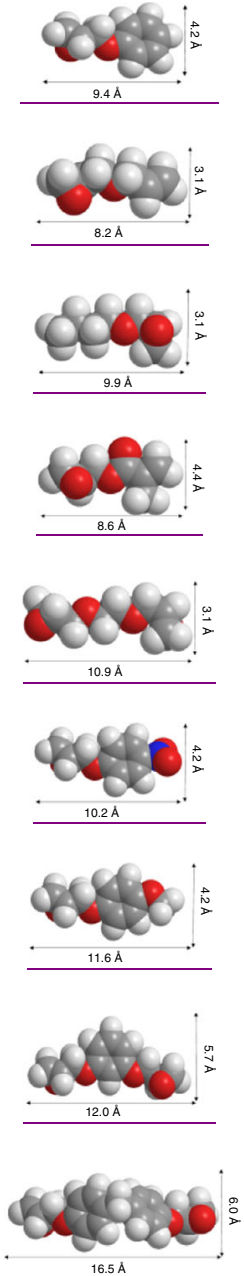

$>99$

$\underline{99}$

$\underline{3960} \quad \underline{1980}$

$\underline{99}$

$\underline{3960}$

$\underline{1980}$

$\underline{98}$

$\underline{3920}$

$\underline{1960}$

$\underline{91}$

$\underline{3640}$

88

$\underline{3508} \quad \underline{1754}$

$\underline{81}$

$\underline{3252}$

$\underline{1626}$

49

$\underline{1940 \quad 970}$

$\underline{14}$

$\underline{572}$

aReaction conditions: epoxide $(20 \mathrm{mmol})$, catalyst $\left(5 \mu \mathrm{mol}\right.$, based on $\mathrm{Zn}_{1.5}$ cluster $)$, and $\operatorname{TBABr}(0.3 \mathrm{mmol})$ under carbon dioxide $(1 \mathrm{MPa}), 373 \mathrm{~K}$ and $2 \mathrm{~h}$ bYield of isolated product was determined from by ${ }^{1} \mathrm{H}$ NMR spectroscopy

cMoles of cyclic carbonate per mole of catalyst Zn-DPA

dMoles of cyclic carbonate per mole of catalyst Zn-DPA per hour

containing Zn-DPA, TBABr, and both, led to only $10 \%$ even hardly any 4-(phenoxymethyl)-1,3-dioxolan-2-one product (Supplementary Table 5, entries 1-3). The subcomponents of $\mathrm{Zn}$-DPA were then investigated independently. $\mathrm{H}_{3} \mathrm{tca}$, abp, or $\mathrm{Zn}$ $\left(\mathrm{NO}_{3}\right)_{2} \cdot 6 \mathrm{H}_{2} \mathrm{O}$ instead of $\mathrm{Zn}$-DPA was applied to $\mathrm{CO}_{2}$ fixation reaction under the same conditions as mentioned above, leading to $11 \%, 12 \%$, and $43 \%$ yield in this product formation (Supplementary Table 5, entries 4-7). Thus, this demonstrated that our MOF Zn-DPA is essential for the cycloaddition reaction of carbon dioxide to epoxides.

We further examined the performance of Zn-DPA in corresponding $\mathrm{CO}_{2}$ cycloaddition reactions, under the same mild conditions, with aliphatic epoxides or aromatic epoxides substituted with different functional groups to check the generality of the catalyst. In the presence of aliphatic epoxides, such as allyl glycidyl ether, butyl glycidyl ether, glycidyl methacrylate, and glycol diglycidyl ether, all gave a high yield ( $>90 \%$, Table 1, entries $2-5$ ). The introduction of nitro- or methoxy-groups onto the phenyl ring gave $\sim 88 \%$ and $81 \%$ of the respective products under the same reaction conditions. Interestingly, as the molecular size of the epoxide substrate increased, the yield of cyclic carbonate decreased significantly, as illustrated by the $49 \%$ yield of 4,4'-((1,3-phenylenebis(oxy))bis(methylene))bis(1,3-dioxolan-2-one) (Table 1, Entry 8). With the bulky epoxide bis(4-(oxiran-2-ylmethoxy)phenyl)methane, there was a dramatic decrease in the yield of cyclic carbonates with only 
a

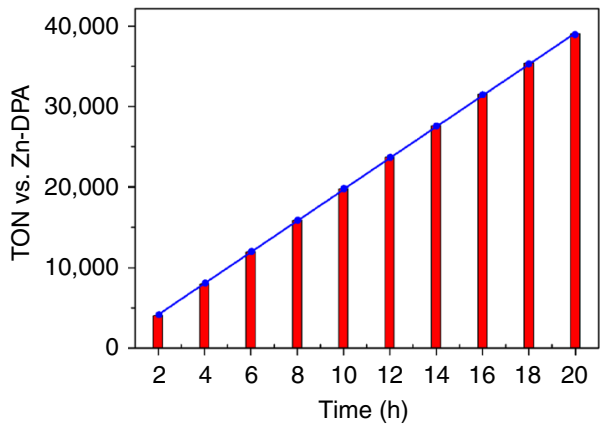

b

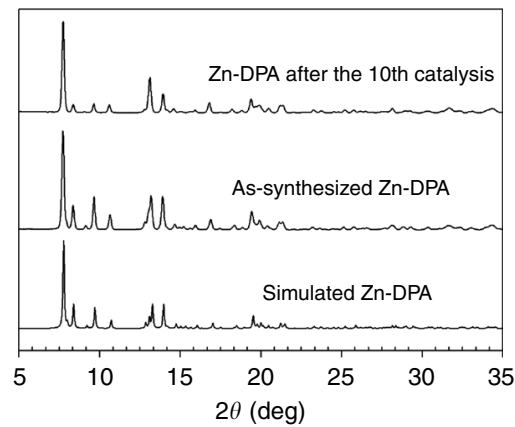

Fig. 3 Reusability of catalyst $\mathrm{Zn}$-DPA. a Time-course and recycling $\mathrm{CO}_{2}$ fixation experiments with $\mathrm{Zn}$-DPA under standard conditions. b PXRD patterns of simulated $\mathrm{Zn}$-DPA (bottom), synthesized $\mathrm{Zn}$-PDA (middle), and $\mathrm{Zn}$-PDA after 10 successive times of the $\mathrm{CO}_{2}$ fixation reaction with 2-(phenoxymethyl) oxirane (top)

$14 \%$ conversion of the reactants, suggesting that the large epoxide substrate restricted diffusion into the pores of Zn-DPA, which limited the access of reactants to the active sites (Table 1, Entry 9) ${ }^{11,32}$, resulting in size-selective catalysis. Such remarkably high efficiency and size selectivity to epoxides in catalytic $\mathrm{CO}_{2}$ cycloaddition confirm that the PCP Zn-DPA is a suitable heterogeneous catalyst for carbon fixation. Notably, the catalytic effect in an open-dense flexible PCP was not different for small and bulky epoxide substrates, which highlights the importance of the adaptable channels for the size-selective catalysis for $\mathrm{CO}_{2}$ fixation (Supplementary Table 6).

FT-IR spectra of Zn-DPA impregnated with a methanol solution of 2-(phenoxymethyl)oxirane (Supplementary Fig. 16) revealed peaks emerging at 1275 and $920 \mathrm{~cm}^{-1}$ corresponding to the characteristic peaks of the Ar-C-O asymmetric and $\mathrm{C}-\mathrm{O}-\mathrm{C}$ symmetric stretching vibrations. A red shift from $1724 \mathrm{~cm}^{-1}$ (free epoxide) combined with its ${ }^{1} \mathrm{H}$ NMR data (Supplementary Fig. 17) indicated adsorption and activation of the epoxide in the channels of Zn-DPA. Density functional theory calculation was carried out to obtain deep insight into the interaction between Zn-DPA and 2-(phenoxymethyl)oxirane molecule (Supplementary Fig. 18). The close contact was observed between the epoxy O atom of substrate and the zinc ion (Zn-O: 3.24(4) $\AA$ ). C-H... interaction was also observed between the phenyl hydrogen atom of the $\mathrm{tca}^{3-}$ ligands and phenyl groups of the substrate, with the shortest separation being 3.14(0) $\AA$. The high density of Lewis acid zinc centers confined within the PCP channels can bind the epoxide through its oxygen atom to activate the epoxy ring and also serve as electrostatic binding site to capture $\mathrm{CO}_{2}{ }^{33,34}$. Subsequently, the $\mathrm{Br}^{-}$generated from $\mathrm{TBABr}$ attacks the lesshindered methylene $\mathrm{C}$ atom of the coordinated epoxide to complete the ring-opening step. This is followed by the interaction of $\mathrm{CO}_{2}$ with the oxygen anion of the opened epoxy ring to form an alkyl carbonate anion, which is then converted to the corresponding cyclic carbonate through the ring-closing step (Supplementary Fig. 20) ${ }^{35-37}$. These combined factors promoted the cycloaddition reaction, resulting in a high catalytic activity of Zn-DPA for the chemical conversion of $\mathrm{CO}_{2}$ to cyclic carbonates.

Recyclability is an essential feature of any catalyst considered for use in industrial applications. Therefore, we investigated the catalytic activity of bulk Zn-DPA filtered from the catalytic reaction. There was no significant decrease in the efficiency of the catalyst even after 10 cycles of the $\mathrm{CO}_{2}$ fixation reaction with 2(phenoxymethyl)oxirane, which yielded a total of $\sim 167 \mathrm{mmol}$ product and a total TON of 39,064 per $\mathrm{Zn}_{1.5}$ cluster of $\mathrm{Zn-DPA}$ (Fig. 3a). It is worth noting that Zn-DPA gave shorter reaction time and higher product yield than the previously reported
PCPs ${ }^{19}$, indicating its suitability for the industrial application in the cycloaddition of the carbon dioxide to cyclic carbonates (Supplementary Table 7). Furthermore, the solid catalyst recovered from the catalytic reaction exhibited the same PXRD pattern as the pristine solid PCP Zn-DPA (Fig. 3b), and the IR spectra also support the maintenance of the structure after 10 cycles catalysis (Supplementary Fig. 19), all confirming the stability of the PCP framework during the catalytic reactions. Meanwhile, at the end of the reaction, inductively coupled plasma analysis of the reaction mixture filtrate revealed no $\mathrm{Zn}$ leaching, indicating that the catalytic reaction is indeed heterogeneous in nature.

\section{Discussion}

In summary, we have successfully constructed a new two-fold interpenetrated PCP that possesses adaptable property for capturing, concentrating, and converting $\mathrm{CO}_{2}$ using a flexible propeller-like ligand. We have demonstrated that the PCP presents efficient accommodation to $\mathrm{CO}_{2}$, which has been confirmed by single-crystal structure analysis of $\mathrm{CO}_{2}$-adsorbed phases. Its inherent $\mathrm{CO}_{2}$ absorbability, exposed Lewis acid metal sites, and well-defined pores allow this PCP to promote effective sizeselective fixation of captured $\mathrm{CO}_{2}$ with appropriate epoxides in a one-pot reaction. Our strategy will open up a new dimension of porous compounds as platforms for determining the gas-loaded crystal structures and efficient utilization of $\mathrm{C} 1$ resources. The key to success is to introduce a durable interpenetrated framework, a local flexibility to induce adjustable capture and catalytic Lewis acid sites in the pores.

\section{Methods}

Characterizations. Elemental analyses of $\mathrm{C}, \mathrm{H}$, and $\mathrm{N}$ was performed on a Vario EL III elemental analyzer. Hydrogen NMR spectra were measured on a Bruker-400 spectrometer with $\mathrm{Me}_{4} \mathrm{Si}$ as an internal standard. X-ray powder diffraction (XRD) patterns of the PCPs were recorded on a Rigaku D/max-2400 X-ray powder diffractometer (Japan) with $\mathrm{Cu}-\mathrm{Ka}(\lambda=1.5405 \AA)$ radiation. Thermogravimetric analysis (TGA) was carried out at a ramp rate of $5{ }^{\circ} \mathrm{C} / \mathrm{min}$ in a nitrogen flow with a Mettler-Toledo TGA/SDTA851 instrument. FT-IR spectra were recorded using $\mathrm{KBr}$ pellets on a JASCO FT/IR-430 spectrometer. Gas adsorption isotherms were obtained on a BELSORP-max adsorption instrument (BEL Japan Inc.) using a volumetric technique. The initial outgassing of the sample was carried out under high vacuum $\left(P<10^{-2} \mathrm{~Pa}, T=120^{\circ} \mathrm{C}\right)$ for $32 \mathrm{~h}$ to remove solvated water molecules. The $\mathrm{CO}_{2}$ adsorption isotherms for desolvated compounds were collected in a relative pressure range from 10 to $1.0 \times 10^{5} \mathrm{~Pa}$.

Synthesis of Zn-DPA-2 $\mathbf{H}_{\mathbf{2}} \mathbf{O}$. A mixture of $4,4^{\prime}, 4^{\prime \prime}$-tricarboxyltriphenylamine $\left(\mathrm{H}_{3} \mathrm{tca}\right)(18.9 \mathrm{mg}, 0.05 \mathrm{mmol}),(\mathrm{E})-1,2-\mathrm{di}($ pyridin-4- yl)diazene $(9.2 \mathrm{mg}, 0.05$ $\mathrm{mmol})$, and $\mathrm{Zn}\left(\mathrm{NO}_{3}\right)_{2} \cdot 6 \mathrm{H}_{2} \mathrm{O}(29.8 \mathrm{mg}, 0.1 \mathrm{mmol})$ was dissolved in ethanol/water $(9 / 1,5 \mathrm{~mL})$ in a screw capped vial. The resulting mixture was placed in an oven at $110{ }^{\circ} \mathrm{C}$ for 3 days. Red block-shaped crystals were obtained after filtration. Yield: 
$82 \% . \mathrm{C}_{26} \mathrm{H}_{20} \mathrm{~N}_{3} \mathrm{O}_{8} \mathrm{Zn}_{1.5}$ : C 52.00, H 3.36, N 7.00\%; Found: C 51.94, H 3.40, $\mathrm{N} 7.02 \%$.

Synthesis of Zn-DPA. Crystals of $\mathrm{Zn}$-DPA. $2 \mathrm{H}_{2} \mathrm{O}$ were heated to $120^{\circ} \mathrm{C}$ in vacuo for $\sim 32 \mathrm{~h}$ to afford single crystals of desolvated $\mathrm{Zn}$-DPA suitable for single-crystal XRD. Anal. calcd. for $\mathrm{C}_{26} \mathrm{H}_{16} \mathrm{~N}_{3} \mathrm{O}_{6} \mathrm{Zn}_{1.5}$ : C, 55.31; H, 2.86; N, 7.44\%. Found: C, 55.36; H, 2.79; N, 7.43\%.

Single-crystal X-ray diffraction analyses. A single crystal was selected to put in a capillary and evacuated at $120^{\circ} \mathrm{C}$ under reduced pressure (below $10^{-2} \mathrm{~Pa}$ ) overnight. Then, $\mathrm{CO}_{2}$ was slowly introduced into the capillary until the pressure reaching 101 $\mathrm{kPa}$ at $195 \mathrm{~K}$. After $10 \mathrm{~min}$ at $195 \mathrm{~K}$ under $101 \mathrm{kPa} \mathrm{CO}$ atmosphere, the glass capillary was sealed using small torch flame. The gas-loaded crystals were mounted onto a Rigaku XtaLAB AFC10 diffractometer equipped with Mo K $\alpha(\lambda=0.71073 \AA)$ optic and slowly cooled down and diffraction data were collected at $183 \mathrm{~K}$. Solution and refinement of this structure were performed through direct methods and fullmatrix least-squares methods based on $F^{2}$ values with SHELXTL version 2018/3.

Typical procedure for $\mathrm{CO}_{2}$ cycloaddition of epoxides. The catalytic reaction was conducted in a $30 \mathrm{~mL}$ autoclave reactor, which was purged with $1 \mathrm{MPa} \mathrm{CO}_{2}$ under constant pressure for $15 \mathrm{~min}$ to allow the system equilibration. The vessel was set in an oil bath with frequent stirring at $373 \mathrm{~K}$ for $2 \mathrm{~h}$. At the end of the reaction, the reactor was placed in an ice bath for $20 \mathrm{~min}$ and then opened. The catalysts were separated by centrifugation, and a small aliquot of the supernatant reaction mixture was analyzed by ${ }^{1} \mathrm{H}$ NMR to calculate the reaction yields.

\section{Data availability}

The X-ray crystallographic coordinates for structures reported in this study have been deposited at the Cambridge Crystallographic Data Centre (CCDC), under deposition numbers 1564761-1564763. These data can be obtained free of charge from The Cambridge Crystallographic Data Centre via www.ccdc.cam.ac.uk/data_request/cif. All other data supporting the findings of this study are available within the article and its Supplementary Information, or from the corresponding author upon reasonable request.

Received: 27 February 2018; Accepted: 9 September 2019;

Published online: 25 September 2019

\section{References}

1. Rackley, S. A. Carbon Capture and Storage (Elsevier, 2010).

2. Hester, R. E. \& Harrison, R. M. Carbon Capture: Sequestration and Storage (RSC Pub., 2010).

3. Nugent, P. et al. Porous materials with optimal adsorption thermodynamics and kinetics for $\mathrm{CO}_{2}$ separation. Nature 495, 80-84 (2013).

4. D'Alessandro, D. M., Smit, B. \& Long, J. R. Carbon dioxide capture: prospects for new materials. Angew. Chem. Int. Ed. 49, 6058-6082 (2010).

5. Chu, S. Carbon capture and sequestration. Science 325, 1599 (2009).

6. Markewitz, P. et al. Worldwide innovations in the development of carbon capture technologies and the utilization of $\mathrm{CO}_{2}$. Energy Environ. Sci. 5, 7281-7305 (2012).

7. Gao, W.-Y. et al. Crystal engineering of an nbo topology metal-organic framework for chemical fixation of $\mathrm{CO}_{2}$ under ambient conditions. Angew. Chem. Int. Ed. 53, 2615-2619 (2014).

8. Lu, X. B. \& Darensbourg, D. J. Cobalt catalysts for the coupling of $\mathrm{CO}_{2}$ and epoxides to provide polycarbonates and cyclic carbonates. Chem. Soc. Rev. 41, 1462-1484 (2012).

9. Schäffner, B., Schäffner, F., Verevkin, S. P. \& Börner, A. Organic carbonates as solvents in synthesis and catalysis. Chem. Rev. 110, 4554-4581 (2010).

10. Vaidhyanathan, R. et al. Direct observation and quantification of $\mathrm{CO}_{2}$ binding within an amine-functionalized nanoporous solid. Science 330, 650-653 (2010).

11. Warren, J. E. et al. Shape selectivity by guest-driven restructuring of a porous material. Angew. Chem. Int. Ed. 53, 4592-4596 (2014).

12. Ma, Y. S. et al. A convenient strategy for designing a soft nanospace: an atomic exchange in a ligand with isostructural frameworks. J. Am. Chem. Soc. 137, 15825-15832 (2015).

13. Foo, M. L. et al. An adsorbate discriminatory gate effect in a flexible porous coordination polymer for selective adsorption of $\mathrm{CO}_{2}$ over $\mathrm{C}_{2} \mathrm{H}_{2}$. J. Am. Chem. Soc. 138, 3022-3030 (2016).

14. Deng, H. X. et al. Large-pore apertures in a series of metal-organic frameworks. Science 336, 1018-1023 (2012).

15. Li, J.-R. et al. Carbon dioxide capture-related gas adsorption and separation in metal-organic frameworks. Coord. Chem. Rev. 255, 1791-1823 (2011).

16. Zhang, T. \& Lin, W. Metal-organic frameworks for artificial photosynthesis and photocatalysis. Chem. Soc. Rev. 43, 5982-5993 (2014).
17. Chughtai, A. H., Ahmad, N., Younus, H. A., Laypkov, A. \& Verpoort, F. Metal-organic frameworks: versatile heterogeneous catalysts for efficient catalytic organic transformations. Chem. Soc. Rev. 44, 6804-6849 (2015).

18. Zhang, J. P., Zhang, Y. B., Lin, J. B. \& Chen, X. M. Metal azolate frameworks: from crystal engineering to functional materials. Chem. Rev. 112, 1001-1023 (2012).

19. Zhou, Z., He, C., Xiu, J. H., Yang, L. \& Duan, C. Y. Metal-organic polymers containing discrete single-walled nanotube as a heterogeneous catalyst for the cycloaddition of carbon dioxide to epoxides. J. Am. Chem. Soc. 137, 15066-15069 (2015).

20. Liu, J. et al. Applications of metal-organic frameworks in heterogeneous supra-molecular catalysis. Chem. Soc. Rev. 43, 6011-6061 (2014).

21. Corma, A., García, H., Llabres, i \& Xamena, F. X. Engineering metal-organic frameworks for heterogeneous catalysis. Chem. Rev. 110, 4606-4655 (2010).

22. Horike, S., Shimomura, S. \& Kitagawa, S. Soft porous crystals. Nat. Chem. 1, 695-704 (2009).

23. Sato, H. et al. Self-accelerating CO sorption in a soft nanoporous crystal. Science 343, 167-170 (2014).

24. Schneemann, A. et al. Flexible metal-organic frameworks. Chem. Soc. Rev. 43, 6062-6096 (2014).

25. Bureekaew, S. et al. Control of interpenetration for tuning structural flexibility influences sorption properties. Angew. Chem. Int. Ed. 49, 7660-7664 (2010).

26. Lee, J. Y. et al. Metal-organic framework materials as catalysts. Chem. Soc. Rev 38, 1450-1459 (2009).

27. Banerjee, M. et al. Postsynthetic modification switches an achiral framework to catalytically active homochiral metal-organic porous materials. J. Am. Chem. Soc. 131, 7524-7525 (2009).

28. An, J., Geib, S. J. \& Rosi, N. L. High and selective $\mathrm{CO}_{2}$ uptake in a cobalt adeninate metal-organic framework exhibiting pyrimidine- and aminodecorated pores. J. Am. Chem. Soc. 132, 38-39 (2010).

29. Perdew, J. P., Burke, K. \& Ernzerhof, M. Generalized gradient approximation made simple. Phys. Rev. Lett. 77, 3865-3868 (1996).

30. Grimme, S., Antony, J., Ehrlich, J. \& Krieg, J. A consistent and accurate $a b$ initio parametrization of density functional dispersion correction (DFT-D) for the 94 elements H-Pu. J. Chem. Phys. 132, 154104-1-154104-19 (2010).

31. Guillerm, V. et al. Discovery and introduction of a $(3,18)$-connected net as an ideal blueprint for the design of metal-organic frameworks. Nat. Chem. 6, 673-680 (2014).

32. Horike, S., Dinca, M., Tamaki, K. \& Long, J. R. Size-selective Lewis Acid catalysis in a microporous metal-organic framework with exposed $\mathrm{Mn}^{2+}$ coordination sites. J. Am. Chem. Soc. 130, 5854-5855 (2008).

33. Caskey, S. R., Wong-Foy, A. G. \& Matzger, A. J. Dramatic tuning of carbon dioxide uptake via metal substitution in a coordination polymer with cylindrical pores. J. Am. Chem. Soc. 130, 10870-10871 (2008).

34. Decortes, A., Castilla, A. M. \& Kleij, A. W. Salen-complex-mediated formation of cyclic carbonates by cycloaddition of $\mathrm{CO}_{2}$ to epoxides. Angew. Chem. Int. Ed. 49, 9822 (2010).

35. Kozak, J. A. et al. Bromine-catalyzed conversion of $\mathrm{CO}_{2}$ and epoxides under continuous flow conditions. J. Am. Chem. Soc. 135, 18497-18501 (2013).

36. Maeda, C., Taniguchi, T., Ogawa, K. \& Ema, T. Bifunctional catalysts based on $m$-phenylene-bridged porphyrin dimer and trimer platforms: synthesis of cyclic carbonates from carbon dioxide and epoxides. Angew. Chem. Int. Ed. 54, 134-138 (2015).

37. Guo, X. Y. et al. New rht-type metal-organic frameworks decorated with acylamide groups for efficient carbon dioxide capture and chemical fixation from raw power plant flue gas. ACS Appl. Mater. Interfaces 8, 31746-31756 (2016).

\section{Acknowledgements}

This work was supported by the Natural Science Foundation of Jiangsu Province for Outstanding Youth (grant number BK20180105), the National Natural Science Foundation of China (grant numbers 21401087, 21401086), PAPD and TAPP of Jiangsu Higher Education Institutions, JSPS KAKENHI Grant-in-Aid for Specially Promoted Research (Grant no. 25000007) and Scientific Research (S) (JP18H05262). We also thank the support from WPI-iCeMS.

\section{Author contributions}

J.W. and P.W. conceived and directed the project. P.W. and J.W. prepared and analyzed all compounds and carried out the gas sorption. Y.Li and Y.Liu performed catalytic measurements. J.-J.Z. and S.S. performed theoretical calculation. N.H. and K.O. assisted the crystallographic study. L.X. and M.J. assisted the PCP synthesis. P.W., J.W. and S.K. co-wrote the paper. All the authors discussed the results and commented on the manuscript.

\section{Competing interests}

The authors declare no competing interests. 


\section{Additional information}

Supplementary information is available for this paper at https://doi.org/10.1038/s41467019-12414-Z.

Correspondence and requests for materials should be addressed to J.W. or S.K.

Peer review information Nature Communications thanks Stephen Argent and the other, anonymous, reviewers for their contribution to the peer review of this work. Peer reviewer reports are available.

Reprints and permission information is available at http://www.nature.com/reprints

Publisher's note Springer Nature remains neutral with regard to jurisdictional claims in published maps and institutional affiliations. (c) (i) Open Access This article is licensed under a Creative Commons Attribution 4.0 International License, which permits use, sharing, adaptation, distribution and reproduction in any medium or format, as long as you give appropriate credit to the original author(s) and the source, provide a link to the Creative Commons license, and indicate if changes were made. The images or other third party material in this article are included in the article's Creative Commons license, unless indicated otherwise in a credit line to the material. If material is not included in the article's Creative Commons license and your intended use is not permitted by statutory regulation or exceeds the permitted use, you will need to obtain permission directly from the copyright holder. To view a copy of this license, visit http://creativecommons.org/ licenses/by/4.0/.

(C) The Author(s) 2019 